\title{
2011 Donald R. Ulrich Awards
}

\author{
Kazuki Nakanishi
}

Published online: 10 May 2012

(C) Springer Science+Business Media, LLC 2012

Since 2003 the Donald R. Ulrich Awards are bestowed by the International Sol-gel Society (ISGS) during the biennial International Sol-gel Conference to young researchers who have been recognized for their distinguished achievement in the field of Sol-gel Science and Technology.

They are conferred in memoriam of Prof. Dr. Donald Ulrich who was a senior Program Manager and Deputy Director of the Chemical and Atmospheric Sciences Directorate at the Air Force Office of Scientific Research from 1975 until 1990. Under his management major new initiatives in chemically synthesized materials (ceramics, ultrastructures, sol-gel processing, non-linear optical and ordered polymers, molecular composites, polymer alloys and multifunctional materials) have been established and had a worldwide impact. They contributed largely to what is known today as the Sol-gel field.

The candidatures for the 2011 Awards were opened to scientists younger than 35 years old by March 2011 whose research in the sol-gel field had already a major impact either in Basic and Applied Science or in Product or Product Oriented R\&D. Five submissions have been received for the first venue and none for the second. They have been analyzed by an International Committee composed of Dr. Florence Babonneau, Chairperson of the ISGS, Co-Editor of the J. Sol-gel Science and Technology

K. Nakanishi $(\bowtie)$

Kyoto, Japan

e-mail:kazuki@kuchem.kyoto-u.ac.jp
(JSST), Dr. Geraud Dubois, Treasurer of ISGS, Prof. Dr. Xiaping Fan, Co-chair of the 2011 Conference, Prof. Dr. Rui Almeida, Chairman of the TC-16 Sol-gel Committee of the International Commission on Glass (ICG), Prof. Dr. Michel A. Aegerter, Editor-in-chief of JSST, the recipients of the 2009 Donald R. Ulrich Awards, Dr. Paolo Falcaro and Dr. Robert Kreiter, and Prof. Dr. Kazuki Nakanishi, ISGS Board member, Co-Editor of JSST, Chairman of the selection committee.

Only one candidate has been selected:

Basic and Applied Science: Dr. Kazuyoshi Kanamori, Department of Chemistry, Graduate School of Science, Kyoto University, Japan.

Besides a diploma and the honor to deliver an invited lecture (see his paper in this issue), he received recent publications on sol-gel science and technology including the "Aerogel Handbook" (eds. M. A. Aegerter, N. Leventis, M. M. Koebel) kindly offered by Springer, as well as a check of 500 US\$ generously offered by Mrs. Eleanor Ulrich.

Dr. Kazuyoshi Kanamori (see figures), was born in August 31 (1977) and received his Bachelor (2000), Master (2002), and Doctor of Engineering (2005) degrees from Kyoto University. During the period, he was a Research Fellow of Japan Society for the Promotion of Science (JSPS) in 2004. After receiving his PhD degree, he worked as a Postdoctoral Fellow of JSPS from 2005 to 2007. He is currently Assistant Professor since 2007 at the Department of Chemistry, Graduate School of Science, Kyoto University, Japan. His research interests are based on synthesis, characterization, and application of porous materials prepared via liquid-phase processes such as sol-gel and living polymerizations in polymer chemistry. His advancement in research was recently awarded by The Ceramic Society of Japan (2010). 


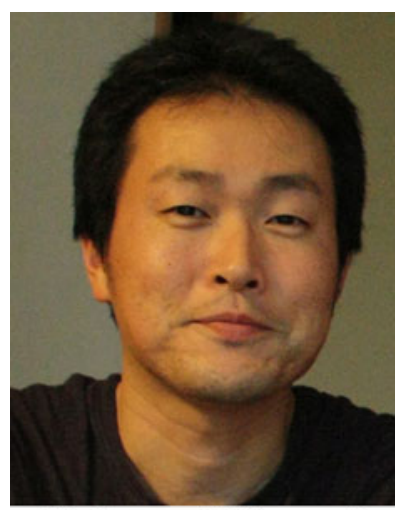

Dr. Kazuyoshi Kanamori

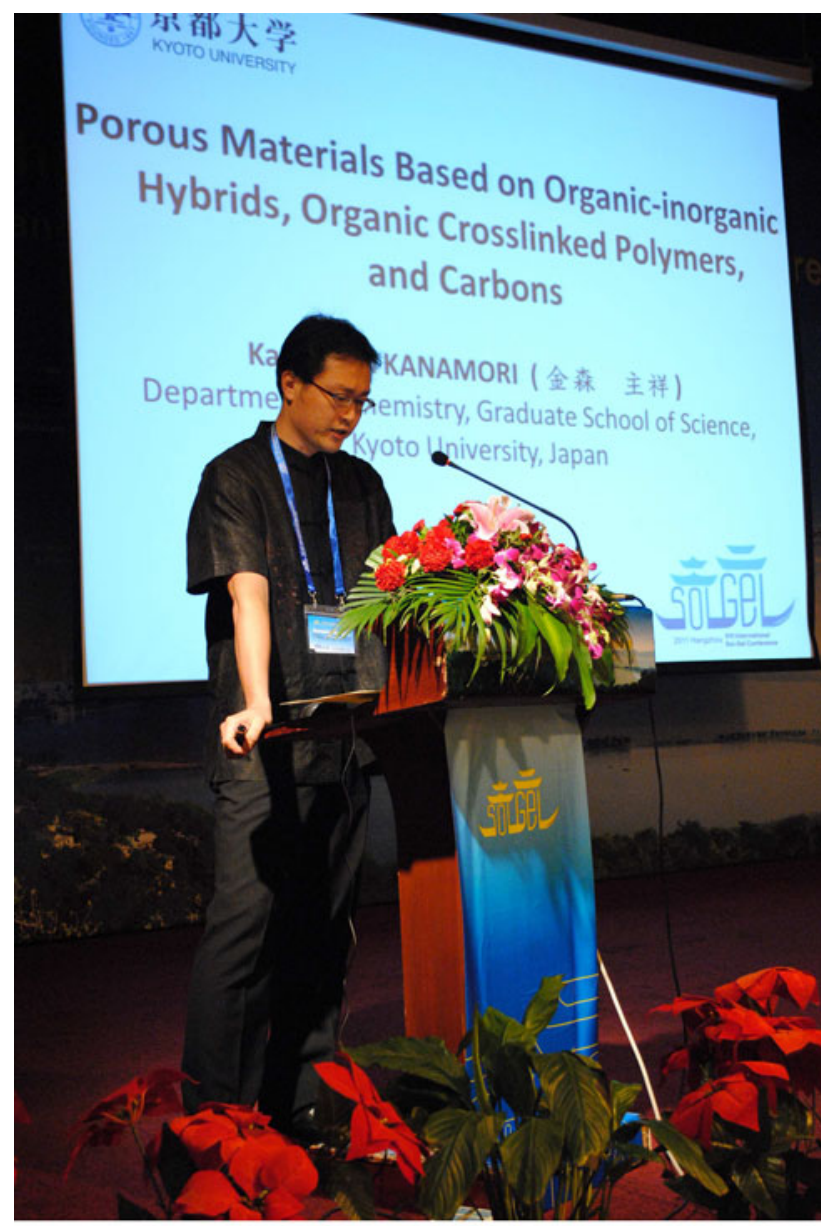

Dr. K Kanamori giving his invited lecture

During his doctoral course, his research was devoted to the study of macropore formations in organic-inorganic hybrid systems using methyltrimethoxysilane (MTMS) as the single precursor. In particular, the pore formation behavior in small confined spaces, which is important for fabricating miniaturized devices, has been investigated three-dimensionally using laser scanning confocal microscopy (LSCM). As a promising application of these materials for separation media, he also demonstrated the excellent separation performances, such as $\sim 100,000 \mathrm{~m}^{-1}$ of theoretical plate number, in high performance liquid chromatography (HPLC). These results summarized in $J$. Sep. Sci. 27, 874 (2004) are gathering a lot of attention, and poster presentations were awarded at the international conferences HPLC 2004 (Philadelphia, USA) and HPLC 2005 (Stockholm, Sweden).

After received the doctor degree, he started working on organic-inorganic hybrid aerogels prepared solely from MTMS. He developed a new 2-step sol-gel system utilizing urea and surfactant, and successfully obtained transparent and low-density aerogels, which show a unique mechanical property like a sponge upon uniaxial compression. Owing to this "spring-back" behavior, aerogellike xerogels can be obtained simply by ambient pressure drying. This was the first report on transparent MTMSderived aerogels and xerogels. For this research he received the best poster award at Sol-Gel 2007 International Conference (Montpellier, France) and the best paper award in 2009 from The Ceramic Society of Japan. He is actively continuing the research to better understand the pore formation and the sol-gel chemistry of organic-inorganic hybrids as well as looking for applications of such materials.

His research is further extending to porous crosslinked organic polymers prepared by living radical polymerization. He regards this systems as an equivalent to the alkoxide-derived sol-gel systems, and for the first time prepared well-controlled macroporous monolithic crosslinked polymers from styrenes, (meth)acrylates and acrylamides. In addition, he demonstrated that polydivinylbenzene can be carbonized and activated under inert atmosphere to obtain activated carbon monoliths with huge surface area $\left(>2,400 \mathrm{~m}^{2} \mathrm{~g}^{-1}\right)$ and preserved macroporosity. He is currently continuing his research to further pursuit the controllability and the potential applicability of porous crosslinked polymer and carbon materials

Thus, Dr. Kanamori has made significant contributions to the basic and applied sciences in the sol-gel field especially for the development of porous materials based on organic-inorganic hybrids, polymers, and carbons. 